\title{
Phosphorus dynamics in a eutrophic coastal system with contrasting bottom water redox conditions
}

\author{
NIELS A.G.M. VAN HELMOND ${ }^{1}$, JACOB CARSTENSEN ${ }^{2}$, \\ MARTIJN HERMANS ${ }^{1,3}$, TOM C. BASTIAAN ${ }^{1}$, DANIEL J. \\ CONLEY $^{4}$, CHRISTOPH HUMBORG $^{5}$, WYTZE K. \\ LENSTRA $^{1}$ AND CAROLINE P. SLOMP ${ }^{1}$ \\ ${ }^{1}$ Utrecht University \\ ${ }^{2}$ Aarhus University \\ ${ }^{3}$ University of Helsinki \\ ${ }^{4}$ Department of Geology, Lund University \\ ${ }^{5}$ Stockholm University \\ Presenting Author: n.vanhelmond@uu.nl
}

Increased anthropogenic nutrient input has led to eutrophication of coastal areas in the Baltic Sea. In many regions, bottom waters have become (seasonally) hypoxic or even euxinic. Insight in the processes responsible for nutrient (re)cycling and removal in these areas is critical to improve water quality. Recent studies suggest that a significant proportion of the phosphorus (P) inputs from land into the Baltic Sea are removed in coastal areas through burial. Particularly archipelagos appear to be a very effective filter for P. It remains unclear, however, how much $\mathrm{P}$ is recycled and in what form $\mathrm{P}$ is buried in sediments, and how both processes are influenced by bottom water redox conditions. Here, we investigate the relationship between bottom water $\mathrm{O}_{2}$ and $\mathrm{P}$ recycling and burial for ten basins in the eutrophic Stockholm Archipelago, capturing a range of bottom water redox conditions, from oxic to euxinic.

Detailed analyses of water column records of dissolved inorganic P (DIP) and $\mathrm{O}_{2}$ concentrations for 1976 to 2018 reveal seasonal variability in DIP and $\mathrm{O}_{2}$ in all basins, except the euxinic ones, where reoxygenation is episodic. Increases in water column DIP per unit decrease in $\mathrm{O}_{2}$ are comparable in all basins. The total increase in bottom water DIP during a full oxic-euxinic transition varied from 6.7 to $12.2 \mu \mathrm{mol} \mathrm{L} \mathrm{L}^{-1} \mathrm{P}$. These results indicate a strong redox-driven recycling of $\mathrm{P}$ from the sediment, likely through $\mathrm{P}$ release from Fe-oxide bound P. Analyses of sediments from all basins, collected in March 2017 and June 2019, indeed reveal enrichments of Fe-oxide bound P in the surface sediments at all oxic and seasonally hypoxic locations. Little of this Fe-oxide bound $\mathrm{P}$ is permanently buried. Organic $\mathrm{P}$ is quantitatively the most important burial sink for $\mathrm{P}$ at all sites. In most basins, there is no evidence for sink-switching of organic or Fe-oxide bound $\mathrm{P}$ to authigenic $\mathrm{P}$ minerals in the sediment. For two basins, our data suggest formation of a vivianite-type $\mathrm{Fe}(\mathrm{II})-\mathrm{P}$ mineral at depth. Furthermore, at the most seaward euxinic site, we find evidence for a role of the manganese carbonate rhodochrosite as a quantitatively important $\mathrm{P}$ sink. 